\title{
Fishing Nets, with Special Reference to the Otter-trawl.
}

\author{
By
}

H. M. Kyle, M.A., D.Sc.

(With Plates I. and II.)

THE increased attention which has been paid within recent years to fishery statistics has revealed, amongst other troublesome things, that the instruments employed play an important part both as to quantity and quality in the result. It is not necessary to discuss whether any of the instruments as now used give a fair sample of the contents of the water or ground, but it certainly is the case that different apparatus will give different samples. Let a beam-trawl and an otter-trawl work for a year over the same ground alongside drift-nets and fixed trammelnets or gill-nets, and we can guarantee that the results will differ from one another. In the case of the drift-nets we should have a few forms probably in large quantity, in the others a great variety of forms, but in different proportions in each. And again, those obtained by the drift-nets would be practically absent from the trawls. It thus behoves the naturalist to make every kind of fishing apparatus subservient to his use, if he desires to obtain even an approximate measure of fish-life in the sea.

Up to the present time the fishing gear employed by naturalists has been that of the practical fishermen, and rightly too. For a naturalist to devise a new and better type of fishing apparatus than exists, he must serve an apprenticeship in the making and working of the old, so that he may share with the practical men the experience of many generations. The danger then arises, however, of his becoming too much enamoured of the one or two special types he himself has had experience of and losing sight of the others. It would be impossible to find a more careful or better description of a trawl and the working of that trawl than the one given by Dr. Petersen for what he calls the "otter drag-seine"; yet an essential portion of 
the trawl was omitted, and the realisation of his ideas consequently has fallen far short of the ordinary beam- or otter-trawl.

The latter, it must be remembered, are the consummation of the experience not of one or two types of fishing apparatus, but of all. They are the successful and highly developed forms of a long series, so that every little part and detail has come at some time under the searching eye of experience. To realise their full worth, one must hark back to the more primitive forms and retrace their development. It is interesting to note that this is just what Dr. Petersen has done. His so-called "otter drag-seine" and its subsequent alterations repeat, to a certain extent, the history of the real otter-trawl, and in his latest work he has attained to the appreciation of the latter in all its parts.

I have not the slightest doubt that Dr. Petersen, with his admirable command of the English language, would be able to give a good account of the English otter-trawl now that he has one in his possession, but his distance from England, where the right names and the relative importance of the various parts might be explained to him, constitute a great difficulty. It seems more appropriate, therefore, that a detailed description should come from the English side.

As stated above, the otter-trawl is the last of a long series of successful and unsuccessful experiments with fishing gear. I think it advisable, therefore, to preface its description with a brief reference to past history and to the various forms of apparatus used in this and in other countries. Not knowing these, one would be unable to appreciate the finer details of the otter-trawl and the advance it has made from the more primitive types.

The numerous forms of fishing apparatus may be classified according to the mode of working them-fixed nets, if they are moored to the beach, or at the bottom of the sea; movable nets, if they are dragged through the water.

The simplest form of the fixed nets is a dam of stones or rushes between tide-marks leading down into a simple "pound" also made of rushes. More advanced forms are seen in the eel-traps of Holland,* the "fyke-nets" and "weirs" of America, $†$ and the salmon stake-nets of Scotland. In all, the principle is the same. A "leader" of network, in some cases two, is placed across the direction in which the fish are supposed to travel, and guides them into a cunningly constructed labyrinth, from which they cannot escape. In rocky parts the leader is removed, and the "pound" simply moored off the rocks in deep water. It may seem strange that the openings, which are of good size, cannot be used by the fish for exit as well as entry,

* The inshore fishing apparatus of the Netherlands. Mededeel over Visscherij, 1899.

† "Fyke-nets," Bull. U.S. Fish Commission, xii., 1892.

NEW SERIES, - VOL. VI. NO. 4. 
but the difficulties of a wasp which has entered a room through a slightly open window are very small in comparison with those of a fish when it is once in the "heart" of the pound.

These nets are only useful for the capture of inshore fish or fish which enter rivers, but there are two forms of fixed nets, probably derived from the "leader" of the pound-net, which are of great importance in sea fishing. These are the gill-net and the trammel. In the former, as the name denotes, the fish are caught by the gills; in the latter they are entrapped in a bag or pocket of their own making.

Though gill-nets are extensively used in this country, it is mostly in the form of drift-nets for fish swimming near the surface, such as mackerel or herring. The net is made fast-at one end only - to the boat, and boat and net drift together. Sometimes the head-line is sunk below the surface by extra leads on the foot-rope when the fish are swimming deep, and they frequently catch fish-for example, whiting-which keep near the bottom as a rule. In one or two places these nets are moored in fishing for herring, and quite within the last few years the old method of sinking the net to the bottom has been revived on the east coast of Scotland.*

In the United States, $\uparrow$ however, gill-nets are, as a rule, fixed nets, and only occasionally drift-nets. The enormous part they play in the American fisheries may be judged from this, that each boat is said to have an outfit of gill-nets which would extend twenty to thirty miles, if set at one time.

The trammel $\ddagger$ is a compound net usually in three layers, of which the two outer are of wide mesh stretched out taut, whilst the middle layer is of very small mesh with plenty of slack. Consequently, if a fish strike the net on either side it will pass through the first layer and drive the second through the third, and thus becomes entrapped in a pocket of its own making. These nets are employed on the southwest coast of England and round the Channel Islands for the capture of red mullet, though they catch all kinds of fish-soles, plaice, dories, and even crabs and lobsters. Like the gill-net, the trammel is moored upright to the bottom by means of lead on the foot-rope and corks on the head-rope, and like it also is very useful on rough or rocky ground. The advantage which the trammel has over the gill-net consists in its

* The result of this is said to have been a greatly increased catch, amongst other fish, of haddock, on grounds which were supposed to have been cleaned out by the trawlers. Gill-nets were formerly used also for the capture of crabs and lobsters on the south coast of England.

† Augur, Bull. U.S. Fish Commission, xiii., 1893, p. 381.

‡ Wilcocks, The Sea Fisherman, London, 1875, p. 244 ; Holdsworth, Deep Sea Fishing and Fishing Boats, London, 1874, p. 175. 
ability to catch different sizes and, therefore, a greater variety of fish.*

The utility of these two forms of nets as complementary to trawls can hardly be overestimated. They reach ground the trawl cannot touch, and might be used in any part of the North Sea. Incidentally, it may be mentioned that the United States Fish Commission steamer Albatross had twelve different kinds of gill-nets and two trammels as part of its fishing apparatus. $\dagger$

There are various other forms of fixed nets, such as the stow-net $\ddagger$ ("Ankerkuilen" of Holland) for sprats and whitebaits, which are used in tidal waters or streams. They are not likely to be of any service in deep-sea fishing, so that further mention of them is unnecessary.

The peculiarity of the preceding nets is that they are, for the most part, stationary, so that the responsibility for being caught rests with the fish themselves. The traps laid are exceedingly subtle, and are the result of generations of experience of the habits, habitat, and even the structure of the fish; but when the traps are once laid man retires, and the fish do the rest. In the case of movable nets man does not wait for the fish to come to him, and, not content with devising ingenious instruments for their capture, pursues them with all his might and drags them in by main force. The two methods of fishing are therefore strongly antagonistic, and cannot both be pursued on the same ground at one and the same time.

It is by means of movable nets that naturalists-in Europe at any rate-have done their work in the past, and the tendency at the present time is to continue doing so. This is founded on the notion that movable nets may be made to give a quantitative measure of the fish in the sea.

The principle of the movable net is simply that of collecting together all the fish within a certain compass and dragging them to land or into a boat. Both these methods seem to have been pursued in the earliest times of which we have definite records by Phœnicians and Greeks. It is from the latter, indeed, that we derive our modern word seine or sean,

* The gill-net is made like an ordinary drift-net. The trammel is usually from 30 to 50 fathoms (60 to $100 \mathrm{~m}$.) long and 1 to 2 fathoms deep. The middle layer is just double this when stretched out. The meshes of the outer layers are from 4 to 5 inches from knot to knot, and those of the middle layer about 1 inch. The foot-rope is weighted according to depth and strength of tide. The price varies according to material used and length. A trammel of 50 fathoms made of cotton and finished completely costs $£ 12$. If the inner wall only is of cotton and the two outer of hemp, about £8. These may be obtained from the well-known Bridport makers (South Dorset), Messrs. Hounsell or Messrs. Gundry.

† Tanner, Bull. U.S. Fish Commission, xvi., 1896.

\# See Wilcocks, loc. cit.; Holdsworth, loc. cit.; Hoek, Verslag Staat Ned. Zeevisch, 1896. 
and it is suggested that the Phœnicians, in the course of their wanderings, taught the use of this net to the men of Cornwall.* However this may have been, it is interesting to note that in passing from the shores of the Mediterranean to the coasts of Great Britain we can mark out every stage in the evolution of the beam- and otter-trawls from the primitive ground- or long haul-seine. The word seine is thus generic, and on historical grounds Dr. Petersen is quite entitled to call his otter-trawl a seine, but so many forms of nets are already included under this term that it is advisable to limit its applicability. In England seine is applied only to those nets which are hauled in on the shore, and so strict is the usage that one and the same net may have different names. When hauled in on the shore it is a seine; when hauled in on a boat it is a tuck-net. Rightly speaking, trawls are therefore tuck-nets, but as these latter are only used from small boats in shallow water, and the term has arisen from the peculiar method of hauling in the net, the word trawl is more strictly applied to the apparatus for deep-sea fishing. Though the fields denoted by these three terms overlap to a slight extent, they are quite distinct, and it prevents confusion to limit the use of the terms correspondingly.

In its simplest form the seine is simply a weighted ground-rope and buoyed head-rope, between which hangs the net. The mode of working is likewise simple. A boat pays out the net some little distance to sea, the ropes attached to each end are brought ashore at a suitable spot, and the whole net is then gradually drawn to the beach.

The changes rung on this simple form are almost too numerous to mention. The length and depth vary, the mesh may be large or small, the size of mesh is different in different parts, the "wings" may be of great length, it may have a "bunt" or "bag" in the centre, and so on. Each kind of net has its distinct uses, and each has its distinct name, as a rule, according to the fish sought after. Usually each net has two sizes of mesh, often three or even four, those in the centre or bunt being smaller than those in the wings, in order to entrap but not mesh the fish. In this form the ground- or long haul-seine is in use in almost all countries of Europe, $\dagger$ but in none is it employed to such an extent as in the United States. All the aids that modern invention can give, a steamer for shooting the net, and steam winches for hauling it in, are there employed.

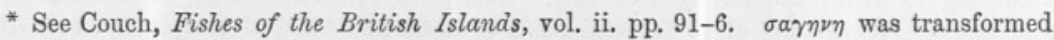
through the Latin Vulgate sagena into the Anglo-Saxon segne, and this has become the English and French seine or sean, the Dutch zegen.

† It is the Tratta or Sciabica of Italy, the Bourgin or Seine of France, the Zegen of Holland. The sight of the swarthy, half-naked fishermen hauling in their long seine on the beach at Posilipo, near Naples, is one of the things which cling to one's memory of that famous city. 
On the south coast of England probably the best-known forms of this kind of net are the sweep-nets for mackerel and pilchard. These are used to surround a shoal of these fish; and a second smaller netthe stop-net-is employed to close the opening in the circle which the large seine is making round the shoal. When the circle is completed the stop-net is removed, and the whole concern is dragged towards the shore if possible. If the fish are exceedingly numerous, another netthe tuck-net-is shot inside the seine, and the fish are removed in batches.*

In the United States $†$ the tuck-net is largely employed, and it may be used any distance from land and over any depth of water. When a shoal of fish has been surrounded the different portions of the lower part of the net are pulled tight together by means of a long "pursestring" passed through rings on the foot-rope. The net is thus "pursed" or "tucked," and the fish cannot escape underneath. The slack of the net is then hauled in until all the fish are collected in the bunt, when the steamer comes alongside, and the fish are ladled on board by means of a bucket.

As already mentioned, the central portion or bunt of these seines has usually a much smaller mesh than the outlying portions or wings. It is also somewhat deeper. In those used for small fish the centre may even be of canvas or calico, as in the sand-eel seines. In Plate I. Fig. 1, a sketch is given of a form of seine which has been much used by members of the Association, especially for small flat-fish. $\ddagger$ The

* For fuller description see Holdsworth, loc. cit. † Augur, loc. cit.

‡ DIMENSIONS OF DRAG-SEINE OR TUCK-NET.

Length of wing (from A to D, Fig. 1), 10 fathoms $(20 \mathrm{~m}$.).

" wide-meshed portion (A to B), 2 fathoms $(4 \mathrm{~m}$.).

", intermediate portion (B to C), 5 fathoms (10 m.).

", small-meshed portion (C to D), 3 fathoms (6 m.).

" "bunt" (E to $\left.\mathrm{E}^{\prime}\right), 3$ fathoms $(6 \mathrm{~m}$.).

Number of meshes in portion from A to B, 30 to the yard ( 31 to metre).

" " , " $\quad$ B to C, $36 \quad, \quad, \quad(37 \quad, \quad)$.

" ", in "bunt" and from C to D, $42,, \quad, \quad(43 \quad, \quad)$.

Cod-end at E' may or may not have a short piece of still finer netting sewed on.

Number of meshes deep at $\mathrm{D}$ and $\mathrm{D}^{\prime}$. . 80 .

", $\quad$ ", across "bunt" from D to $D^{\prime} \quad 80$.

The mode of "setting-up" the net on to the foot-rope is shown in Fig. 2, and to the head-rope in the central portion of Fig. 3. Across the "bunt" and in the fine portion of the net there are four meshes to every "setting." There are therefore twenty "settings" across the "bunt." Across the "bunt" the "settings" are stretched tighter on the head-rope than on the foot-rope, so as to allow more slack in the net underneath. Towards the outer end of the wings the number of meshes on each setting is gradually reduced to three. Small pieces of sheet-lead are fastened to the foot-rope every three to four settings, and small pieces of cork are attached to the head-rope at corresponding distances, but more lead and corks are placed on the "bunt" than on the wings.

The net as a whole is made of 21-ply cotton; the head-rope is of 3 -strand hemp, and 
advantage of this net is its handiness: it may be packed into small compass, and can be worked by two men. It may be used either from the shore or as a tuck-net from a boat. The method of working it as a tuck-net is the same as that employed by the Danes for their so-called plaice-seines. The boat is moored some distance from the shore, and the net carried round by rowing and the help of the tide in a semicircle-in Denmark a second boat may aid in shooting itthen the net is dragged over the ground by hauling on the anchorrope. When the boat is close over the anchor, the net is quickly hauled in, care being taken to keep the foot-rope tight and the head-rope slack, i.e. to "tuck" the net.

The Danish "tuck-net" and plaice-seines are probably the same as the above, but the lack of any description of them prevents certainty on the point. It is very similar to Petersen's otter-trawl, but has no "funnel" in the bunt. This is an advantage rather than the reverse, because the mesh is already so small that any additional impediment would prevent the water passing freely through the "bunt," and thus inhibit its fishing capability. Pockets are only of use when the apparatus having them is working for some time-an hour or more. In these fine nets for shallow water they are unnecessary as well as an impediment, because the gear is hauled in at short intervals.

Since the ground covered by these ground-seines, plaice-seines, or tucknets is necessarily limited, we may endeavour to increase it in two ways - by fixing otter-boards to the end of the wings, or by towing the net between two boats. The former method was adopted some twenty years ago by the Danish fishermen, and will be referred to more particularly later. The latter seems to be an ancient method, and, as it displays the historical development of our modern English trawls, may be briefly described here. It is the ordinary method of deep-sea fishing on the southern shores of Italy (the cocchia);* of France (filets de boenf); ${ }^{*}$ and of Spain (parejas).

In the filets de boeuf the spread of the net is about 80 feet $(25 \mathrm{~m}$.); and, since the boats in towing separate as widely from one

the foot-rope of 4-strand hemp. At the end of each wing both head-rope and foot-rope are continued out one foot, "hitched" round a pole six feet high, and meet together ten to twelve feet further in an "eye." The drag-ropes, thirty to fifty fathoms long, are fastened to each "eye." A heavy piece of sheet-lead is fastened round each pole just above where the foot-rope is hitched on $(\mathrm{L})$.

The complete net as above described costs £5. A larger net of same make, 100 meshes in the "bunt" and twelve fathoms in the wings, costs a little over $£ 6$.

* Faber, The Fisheries of the Adriatic; Gourret, Les Pécheries et les Poissons de la Mediterranée, Paris, 1894.

In the Italian trawls there is a series of four to five hoops, probably of bamboo, which help to support the main body of the long net. 
another as possible, these nets may have as wide a spread as our otter-trawls. The wings are somewhat smaller than those of the dragseine above mentioned, but the bag is of enormous dimensions. From the centre of the head-line to the end of the sac (culignon) it measures at least 90 feet $(28 \mathrm{~m}$.). As in the drag-seine, the meshes are very small-1 in. at the greatest-and there are no pockets; instead, the culignon has the form of a triangle whose apex joins the main body of the net. The base of the triangle, i.e. the end of the net, expands at each side into two ears (anses), and from the centre of the base two stout cords-one below, the other above-run up through the net to join the foot-rope and head-line respectively. The object of this evidently is to press the fish into the ears and keep them there. There is thus no need for flapper or pockets. The whole contrivance is, however, very clumsy in comparison with the ordinary beam- or ottertrawls.

In the tartana fishing of Italy and the gangui à la voile of France there is only one boat for each net. The nets differ considerably; in the gangui it is similar to the filet de bouf; in the tartana it is much simpler, without wings or pockets. Both are alike, however, in having a long pole of wood fixed some little distance in front of the net in order to keep the mouth open. The boat which drags the net drifts with the wind and tide, as is the case with the eel-drift boats of Denmark. In the latter, however, the net has no beam or pole, but the bridles are carried directly to the boat, the one forward to the end of the bowsprit, the other aft to the mizzen boom.

From these somewhat primitive types to the modern English beamtrawl* there is a considerable gap, but the beam-trawl is highly specialised, and the early stages are quite lost. It differs from the previous forms in having the top of the net fastened directly on to the beam, which again rests on triangular pieces of iron, called the iron-heads. The honour of introducing this change has been claimed by the fishermen of Barking on the Thames, and Brixham in South Devon. For the later developments, however, the lengthening of the square and introduction of pockets and flapper, the Brixham men seem responsible. Since the description given by Holdsworth leaves nothing to be desired, it is unnecessary to enter into any details of its structure. $\dagger$

We come lastly to the otter-trawl, the most recent and most efficient

* For an excellent description of the structure and working of the beam-trawl see Holdsworth, loc, cit.

† The size of mesh used in the beam-trawl varies according to the kind of fishing. For whiting the mesh in the square is $2 \frac{1}{2}$ in. to $2 \frac{1}{4}$ in. from knot to knot, and this decreases to $1 \frac{1}{2}$ in. and then to $1 \frac{1}{4}$ in. towards the cod-end. For ordinary fishing the size of mesh is as in the otter-trawl. 
of all trawls. Its introduction is of so recent a date that changes and experiments are still being made-on the boards, the size and shape of the net, ground-rope, and so on, so that it seems as if the final form had not yet been attained.

The principle of this trawl, as is well known, is that of the kite, the net representing the "tail," the boards the body of the kite, and the warp the string. When a current of air strikes on the kite it tends to drive the kite as a whole away from the string, but the lower portion, being the larger, tends to go away from the string more than the upper. Hence the head of the kite tends to incline towards the string, and consequently the kite, as a whole, moves upward until it has reached such an angle to the direction of the wind that the forces acting above and below the line of the string are in equilibrium. The otter-boards act in a similar fashion when drawn through the water.

Though the principle of the otter-board had been long known, and in use for carrying out a line from the beach or the side of a boat, it was not until between 1860 and 1870 that experiments were made with it on trawls. The earliest mention I can find is that made by Holdsworth (loc. cit.) in 1874, and the invention is there ascribed to a Mr. Musgrave. From other evidence it appears, however, that Musgrave merely introduced the otter-trawl to the notice of Irish fishermen, and that Mr. Hearder, an electrician and inventor of considerable repute, was really the inventor.

One can see from the figure given by Holdsworth that the original otter-trawl invented by Hearder differed from the modern trawls in that the ground-rope was very little behind the head-rope. The boards, however, were fixed up in a similar fashion to those later patented by Scott. These trawls were much used by amateurs, especially from steam yachts, but it was not till some years later that professional fishermen adopted them.

According to Spillmann, ${ }^{*}$ the captain of an English steam trawler was the first to experiment with them in 1885 , but he does not seem to have met with success. In 1886 one Thurlow took out a patent for a peculiar kind of board resting on a small trolley, but this also does not seem to have worked well. In the Mittheilungen for 1888, p. 153, a figure is given of an otter-board which is fixed up essentially the same as those now used. It was employed by the Danish sailing craft from Frederikshaven when fishing on the west coast of Jutland. If the wind was suitable they fastened these otter-boards to their long drag-seines (or plaice-seines, see ante), and towed the net over the ground ("snurrevaaden"). As the fishing seems to have been success-

* Mitt. Deut. Seefisch. Vereins, August, 1896, p. 153. 
ful,* we may ascribe to the Danish fishermen the honour of first using, professionally, the otter-trawl from sailing boats.

It was not, however, until 1894 that the otter-trawl began to make distinct headway amongst professional fishermen. In that year Scott of Granton, who had been experimenting for several years with the otter-boards, became at last convinced of their utility and took out a patent for boards of his own design. He then fitted up several steamers on his own account and caused them to fish from different English ports in succession. The transformation effected thereby in the fishing apparatus of the English, and later the foreign, steamers was both rapid and extensive; within a few years the old beam-trawls had quite disappeared, except in the sailing craft. $\uparrow$ The advantages claimed for the otter-trawl over the beam-trawl were mainly that it had a greater spread, and that its head-line was higher from the ground, so that it should catch more fish and in greater variety. $\ddagger$ Recent investigations have cast some doubt on the first claim, but the second seems to be well substantiated by the greater catches of round fish which the otter-trawl brings in.

From the figure of Scott's patent otter-boards given by Cunningham in this Journal (loc. cit.) it appears that, as originally designed, the groundrope and head-line met together in a ring at the centre of the hind margin. In all the boards used at the present day they are fastened separately, the former near the foot of the board, the latter near the top. In the present-day boards also, there are three transverse iron bars running across the otherwise smooth front face and bolted through to similar bars on the back. On the latter, one frequently sees two long iron bars placed diagonally across the board. These are used on the boards with chains in place of the patent triangles.

The boards are made of deal wood and are $9 \mathrm{ft}$. to $10 \mathrm{ft}$. long by $4 \mathrm{ft.} 5$ in. to $4 \mathrm{ft.} 6$ in. high, and 4 in. to 5 in. thick. $\S$ The first iron bar is placed $2 \mathrm{ft} .4$ in. to $2 \mathrm{ft}$. 6 in. from the anterior border and supports the base of the first triangle or "bracket" (see Cunningham's figure). The second bar comes 18 in. further back and supports the second and longer triangle. In working, the two triangles meet about

\footnotetext{
* Petersen, Report from the Danish Biological Station, iii., 1892, p. 36. Mitt. Deut. Seefisch. Vereins, 1888.

† According to Spillmann, loc. cit. (quoted by Petersen, loc. cit., 1898), Capt. Nielsen, a Dane, was the first to make the otter-boards a success in 1895. As Scott and probably many others had been successful during 1894, it would have been more correct to say that Nielsen was one of the first successful fishermen. It appears further from Spillmann's account that Nielsen was one of the first, if not the first, to avoid Scott's patent by using chains instead of "brackets" on the boards.

‡ Cunningham, "North Sea Investigations," Journ. M. B. A., iv. pp. 114-121.

$\S$ According to Spillmann the boards used in Germany are shorter (7 ft.) and lighter ( 7 cwt.), but in proportion higher $(4 \mathrm{ft}$.). The English boards are about 9 cwt.
} 
9 in. to $1 \mathrm{ft}$. from the board and nearer the base of the anterior triangle than that of the posterior. The third iron bar is placed near the posterior margin of the board, a little in front of the two holes above and below for the end of the head-line and the shackle of the foot-rope respectively. Round the apices of the triangles a ring or shackle is passed, which, when the boards are working, is fastened to the last of a series of iron links, six to ten in number, forming the continuation of the warp. The second last link of this chain is replaced by a swivel which serves to take the "turns" out of the warp. In the non-patent boards chains are used in place of the brackets, and they are fastened to the boards nearer to the posterior end, as well as wider apart. The reason for this is that the solid iron brackets of Scott's patent are able to steady the board, though they act on only a small surface. The chains are loose and must, in order to steady the board, be attached as near the corners as possible.

Other forms of boards have been tried, but these are the ones most used. The great difficulty with them all is that when the boat stops towing, or if the warps get slack for any reason, the boards fall flat on the ground. When the strain comes on the warps again the boards, instead of rising to their previous position, may turn right over, and thus put a double turn on the net.

To try to obviate this an otter-board of peculiar shape was patented in Germany in 1897. In this, two large wheels joined by an axle were employed, and in the centre of the axle two oar-shaped spars were fixed-one above, the other below. These spars were inclined at an angle away from the axle, so that the upper should catch the water as the ordinary otter-boards do, and the lower the ground in similar fashion. From the sides of the axle two iron bars extended forward to the inner side, and to the ends the warp was attached. Two other similar bars extended backward to the toe-chain of the foot-rope, and from a little distance along them two chains passed upward and backward to support the pole which held up the head of the net.

Whether these have been successful or joined the majority of patents, I cannot say.

It is still an open question whether the large size of boards used by the trawlers is really necessary. The great resistance they offer to the water and their great weight add considerably to the pull of the net on the warps, and consequently demand more power and steaming on the part of the steamer. Further, the volume of water displaced causes a strong current to rush back against the wings. If this water passed down into the net it would be an advantage, but it is found that even with double meshes on the head of the wings it is necessary to leave a gap between the boards and the net. It might be thought, therefore, that if an opening 
were made in the centre of the board-which plays little or no part in the rotating motion already described - then the same purpose would be served, and if they had sufficiently large surfaces in front and behind the line of action of the trawl warp, they would act just as well as the ordinary boards. Such boards have been used for some months on the trawl of the Association's steamer Oithona, and so far as one can judge, give as good a spread, and are easier to work with than if they were solid throughout.

The net of the otter-trawl has gone through several changes since first introduced, and even now there are many differences in detail in different companies' trawls. In comparison with that of the beamtrawl, it has a shorter "square," but this is compensated for by an additional pair of wings on the top, or rather in front. In other words, the beam-trawl net has only one pair of wings-the bottom pair; the otter-trawl net has two. The "bag" of the net is identically the same in both.

The "head-line" is formed of a single rope, which passes from board to board along the front of the net above. It is $3 \mathrm{in}$. to $3 \frac{1}{2} \mathrm{in}$. in circumference, and is usually from 90 to 100 feet long. Before use it must be well soaked in water for some time, stretched, then soaked again. This prevents the rope from twisting itself up or "kinking," as it is called. The best thing for a head-line is a half-used warp or a rope which has seen some service and had the "kinks" taken out of it.

The "square" is the central portion of the net which overhangs the ground in front of and above the ground-rope in trawling. It is socalled, I imagine, because it is the nearest approach to a square piece in the whole net. The "top of the square," i.e. the portion immediately behind the head-line and the "top-wings," has 300 meshes across (sometimes as many as 330). The "bottom of the square," the portion immediately above the inner edge of the "ground-rope," has 200 meshes across, and down each side there are from 100 to 120 meshes, according as one has a square of 34 or 40 feet long. The size of the mesh is the same throughout, namely, 3 in. from knot to knot, or "four fingers' breadth," as the fishermen say.

The "top-wings" are the outlying portions of the net which extend forward from the square on each side to the top part of the boards. They are of a peculiar triangular shape, with a broad base of 100 meshes joined on to the head of the square, and an apex of only 6 to 12 meshes at the boards. Each may be from 31 to 35 feet long, according to the fancy of the fisherman for a long or a short square. These parts are made to suit one another and the lower portion of the net. As the latter seldom varies, it follows that the top-wings must 
vary inversely as regards the square. The mesh of the top-wings is usually the same as that of the square, viz. 3 in., but sometimes it is only $2 \frac{1}{2}$ in.

Measuring along the side, the top-wing and the square taken together are 65 to 70 feet in length, and this consequently is the length of each "bottom-wing." * These form the lower portions of the trawl-mouth. In front, they are fixed to the ground-rope; at the sides, to the square and top-wings; and behind, to the head of the belly. In shape, they are long, comparatively narrow strips, which are about twice as broad (or deep) at the lower or hind end as they are at the upper or forward end. Where they join on to the head of the belly they measure 50 to 55 meshes across; at the forward end next the boards they are from 25 to 40 meshes. Some men prefer a deep lower wing with 40 meshes in front; others like it narrower. The size of mesh is again $3 \mathrm{in}$. from knot to knot.

When we come to the "bag" of the net we find that the upper and lower portions are exactly alike, so that as they come ready-made from the makers, it is impossible to distinguish them; and one may be used for the other. Formerly, ten more meshes were allowed in the head of the top portion than in the lower, as is always the case in the beamtrawls; but nowadays the nets are shaped and fixed differently, and the ten meshes are unnecessary. The upper and lower portions are thus alike, and each is divisible into two. The first part, where the number and size of the meshes are being reduced, is called the "batings" when above, "belly and batings" below; and the second part, which is the end of the net, is the "cod-end" or "cod."

The "batings" start with 200 meshes across where they join on to the foot of the square and work down to 60 . The size of the mesh to begin with is $3 \mathrm{in}$. from knot to knot, and this is reduced to $1 \frac{1}{2} \mathrm{in}$. The distance between the 200 mesh and the head of the 60 is 34 to 36 feet measured along the side; and the "cod-end," which is uniformly of 60 meshes across, is 12 to 18 feet long. The length of the "bag" is thus from 46 to 50 feet.

In the "batings" the reduction of the size of the mesh and of the number of meshes across is made as gradual as possible. For the first 8 feet the mesh is still 3 in. from knot to knot, but "batings" $\dagger$

* This is the length of the bottom-wing when fixed to the square and top-wing. In reality, it is some 4 to 6 feet longer. See p. 578 .

† A "bating," i.e. reduction, is where two meshes of the preceding row are taken into one mesh. A "creasing" is where an extra mesh is inserted. "Braiding" is the process of making a net. To braid one "round" is to go once across the net. This closes the half-meshes of the preceding "round." Therefore two rounds are required to make one "row" of meshes. The "batings" and "creasings" constitute the puzzle and the artfulness of the net. 
are made on each side, so as to reduce their number. At the end of 8 feet the mesh is reduced in size through 2 feet to $2 \frac{1}{2} \mathrm{in}$. The batings continue with two knots between each, and the mesh is also gradually reduced until at 18 feet from the foot of the square we have 120 meshes of 2 in. across. This marks the "head of the pockets." The size of mesh is now reduced to $1 \frac{1}{2}$ in., and the batings continued until the "cod" of 60 meshes across is reached. The "cod" is open at the end across the whole 60 meshes. A loose double mesh is braided on at the end, through which a rope is passed. When the cod-end is fastened, this rope is pulled tight at both ends and then fastened in a peculiar and handy knot, which only the true trawler knows. The "flapper" is a short tongue of netting of $1 \frac{1}{2} \mathrm{in}$. mesh, 40 to 50 meshes at the top down to 20 or 22 meshes at the bottom.

The different parts of the net have now been described. It remains to show how they are "fixed" or put together. The "fixing" is the secret of the successful working of the net. By diverse signs one learns to know that the net is too tightly pinched at one part or too slack at another. After a new net is placed in the water it may shrink unevenly-and usually does-and the net will not fish properly. In all cases, when from some sign one suspects the fixing to be wrong, it is better to take the net to pieces and set it up afresh. There is nothing more tantalising than a badly fixed net.

As it comes from the makers the net is in separate bundles, viz. a pair of top-wings, a pair of bottom-wings, the square, a pair of batings and a pair of cod-ends. Unrolling the top-wings and the square, these are braided together, as shown in Plate I. At the side, it is usual to join them by double twine so as to strengthen the corner of the net. The lines of junction of the top-wings to the square are called the "top-quarters" (Plate II.).

The foot of the square is then braided on to the head of one of the batings, and one of the cod-ends to the foot of the latter. The flapper is now taken and laced on to the lower part of the batings where the latter is 90 meshes across. The top part of the net is now ready for fixing on to the lower part. As sent out from the makers the bottom-wings are joined together at their broadest part by three to four rows of meshes of double twine. There should be 100 meshes across from wing to wing, and these form what is called the "bosom." The bosom in the centre and the wings at the sides are to be braided on to the head of the belly or batings, and on the lower end of these is braided the remaining cod-end.

The two halves of the net are now prepared for lacing. This is done by hitching them up to a post, or an eye on the bulwarks, and stretching them out parallel to one another-the flapper on the inside, 
of course-so that the meshes along the side- "selvage," it is calledcorrespond above and below. In lacing it is better to begin at the cod-end and work along to the wings, because the "bag" must be uniformly alike above and below, whereas a little slack, which may show itself in the lacing, does not matter in the wings. The selvage is of double twine both above and below, and the lacing strings, also double, should take in two to six extra rows of meshes. There should be little chance, therefore, of the net breaking away in the selvage.*

When both sides of the net are laced up, the lower portion should be stretched out flat and the pockets put in. This is done by getting hold of the net where it is 120 meshes across, and lacing the top to the bottom part across the first three meshes on each side, then down some ten feet along a line of the network. As the lacing proceeds, the first two meshes of the sides of the flapper are taken up and laced in between the bottom and top part of the net. At 90 the pockets end, but the flapper is laced down to the belly some two feet further along the same line of network. About six rows of the flapper are left free at the end. By lacing the flapper down to the belly a free space is left above, between the flapper and the top batings, so that when fish get behind the flapper and try to strike back they will enter this space first of all, and thence be guided into the pockets.

When the trawl is laced up the last operations consist in fixing on the head-line and foot-rope. The "foot-rope" or "ground-rope" is a very large and expensive structure in the modern trawls. It has a central core of " $2 \frac{1}{2}$ " in. wire covered by old netting from mackerel or herring nets, and this is rounded with old manilla trawl warps. When complete it measures about $10 \mathrm{in}$. in circumference and 120 to $138 \mathrm{ft}$. long.

In order to fix on the ground-rope, the centre of the bosom should be found and hitched up on a pole as before; the wings are then stretched parallel to one another and their ends hitched up to another pole. The "balch" or "balch-line," or rope $1 \frac{1}{2}$ in. in circumference which comes between the ground-rope and the net, is then hitched up at its centre to the first pole and both sides stretched out parallel to some distance over the parallel wings. The bosom of the net is then "marled" on (Fig. 3) directly to the balch. The wings, however, have what is called the "flying-mesh" along the inner side (Fig. 3), and the balch is fixed on differently. A "wing-line" of the ordinary net-twine, but doubled, is passed through each flying-mesh, as shown in the figure, and then marled on to the balch-line. The flying-mesh for the wings is an ingenious contrivance. The part most liable to injury from stones or "ross" on rough ground, is the first two to three

* When heavy "bags" are experienced, a 2-in. rope is laced in with the selvage. 
rows immediately behind the foot-rope. The more yielding or "give" the meshes in these rows have, the more likely are they to jump the obstacle or break it off. This greater elasticity is provided for by the flying-mesh. It is specially useful in the wings, because any obstacle that catches the net will there strike the mesh on the side, i.e. at its weakest part, and might break across a long series of meshes. Such a tear is about the most awkward to mend the fisherman can have. With the flying-mesh the tear tends to be along the mesh, i.e. the course of braiding, and it is soon mended. It is evident further that in the bosom the flying-mesh is unnecessary. The ground-rope is next made fast and stretched out as was done to the net and balch, and the balch is then fastened or "balched on" to it. As a rule 10 to $20 \mathrm{ft}$. of bosom are allowed on the foot-rope, so that the 100 meshes are to be gathered together, in threes, and their balch-line distributed uniformly over the 10 to $20 \mathrm{ft}$. The fisherman is guided by the turns in the rounding of the ground-rope where to fix the "setting." It is generally every third turn for the balching of the bosom. In balching the wings the foot-rope is often marked by chalk-lines where the settings have to go. Experienced hands, however, are guided by the turns in the ground-rope, about every seventh to begin with, until they see how much slack they have, and then fix according to their liking. Three to four of the "staplings" on the balch-line are included in a setting, and the settings are wider apart near the end of the wings than at the quarters.

The head-line and the top part of the net are set up for balching in a similar fashion, but there are no flying-meshes * nor balch-line. The square and the top-wings are marled on directly to the head-line with double twine. The square has very little slack given it; the slack is put into the wings. The result of this is that when the trawl is moving through the water the wings are greatly distended at each side, thus tending to keep the mouth of the bag open wide. If the slack were put into the head of the square, the head-line would dip in the centre from the weight of the net behind.

When the net has been fixed in the fashion described, attention has to be paid constantly, when fishing, to the condition of things at the quarters. These are where the square and top-wings (or belly and bottom-wings) meet on the head-line (or ground-rope). These are made specially strong with double meshes, as already described; and if the net has been badly fixed or shrinks unequally, they soon show it. If the square is too much stretched, it will break away from the head-rope at the quarters; the top-wing has then to be unlaced from

* The flying-mesh may also be present in the top-wings. 
the bottom-wing on the side where the break occurs, more slack given to the square at the quarters, and the whole laced up again.

Some of the finer details in the structure and fixing of the net may now be pointed out. It will first of all be noticed that whilst the head-rope is only 90 feet long, the length of the wings and head of the square which fix on to the head-rope is more than 105 feet, that is to say, 15 feet of slack must be distributed along the two wings. This means that the square is stretched out in the centre as far as it can stretch. The batings are consequently stretched out in the centre, and likewise the cod-end. If we turn to the under part of the net we find the same thing. The ground-rope is 120 feet long, but the length of net to be attached to it is over 160 feet. This means that the centre of the belly must be pulled up, even though plenty of slack is allowed. Consequently, there is a strain down the centre of the net, both above and below, from the front to the cod-end; and this does away with the necessity for having guy-ropes leading from the head-line and footrope to the cod-end, which are present, as mentioned before, in the filets de boeuf.

On the other hand, the bag-formation at the sides, which the Frenchmen obtained by means of these ropes and the ears (anses) in the "cod-end" (culignon), is given in the otter-trawl by a careful distribution of the slack along the sides. The top-wing and square measured along the side are about 70 feet long; the bottom-wing to which they are laced is 5 feet longer. This 5 feet of slack must be put in somewhere, and as it is usual to allow the square two or three of slack in order to relieve the strain on the net and put it on the head-rope, we must distribute the 8 feet of slack on the bottom-wing along the selvage of the top-wing. It would seem, therefore, as if the meshes of the top-wing ought to be stretched, but, as already pointed out, it has about 8 feet of slack along the head-line. The bottom-wing, relatively to the head-rope, has consequently about 16 feet of slack net, and relatively to the foot-rope it has more than 20 feet. The result is that the net must bulge out to the side and also backward, and this is the case with the under part of the net more than with the upper.

As we follow the lines of the bag of the net from the 120 mesh towards the cod-end, it will be noticed that the inner sides of the pockets really continue the sides of the net, and the opening under the flapper is the termination. The remaining portions, formed by the pockets and cod-end, are just as if they had been tacked on separately. When the net is fishing, therefore, there is nothing at the sides to stop the flow of water or cause an eddy, but a smooth passage right down into the cod-end. The rush of water into the latter must be of 
considerable force, and as it enters it must divide into two streamsone to the right, the other to the left, because it cannot pass through the knot by which the end is tied.

The water in the cod-end tending to escape at the sides and above, forms an eddy in the direction of the pockets. That this eddy must be fairly strong is shown by the practice of the fishermen in having a long cod-end. If the cod-end is short and dirt gets in, the fishermen get no fish, and ascribe this to the dead-water or back-wash which gets above the flapper and closes it. And as evidence of this one may find some dirt or weed hanging above the flapper.

With respect to the cod-end, it should be mentioned that rubbers are laced to it underneath to prevent the net being chafed on the ground. They are made from old net cut into strips two to four feet long, and the breadth of the cod-end. They vary in number from four to eight, according as the ground is smooth or rough. On smooth ground, indeed, they are not necessary.

It has been shown above that there is a strain upon the meshes of the net along the central line both above and below. One result of this is that the meshes of the square must be wide open; and since the meshes there are large in size, many fish must escape through them. By Dr. Fulton's experiments * with cod-ends of various sizes of mesh it has been shown that more fish escaped than were captured with the ordinary cod-end mesh of $1 \frac{1}{2} \mathrm{in}$., and when a mesh of $2 \frac{1}{2} \mathrm{in}$. was used all except the very largest got through. A few years ago, also, it occurred to the men of the smaller Brixham trawlers that many fish, especially whiting, must escape through the top of the net, which at that time had a mesh of $2 \frac{1}{2}$ in. in the square and head of the batings. To test the point they laced a portion of a herring net over the square and batings, and found, just as they expected, that they caught more fish in the herring net than in the trawl. They consequently reduced the mesh to $2 \frac{1}{4}$ in. and $2 \mathrm{in}$. in the square, and 2 in. in the batings. Even with this size they find that a great number of intermediate size of whiting-9 to $10 \mathrm{in}$.- are meshed in the batings whilst trying to escape.

It follows from these experiments of Dr. Fulton and the Brixham men that only a very small proportion-less than 10 per cent.—of the round fish are taken by the otter-trawl from the water which it passes through. Some might wonder why the fishermen use such a mesh in the top part of the net as will allow the largest haddock to escape, but the large mesh is really a necessity in the trawls as now constructed. It is different for a beam-trawl, where the mesh can be suited by the speed; but with the otter-trawl the smaller speed which

* Rep. Scot. Fish. Board, xix., for 1900, part iii. p. 62.

NEW SERIES, - VOL, VI, NO, 4. 
is demanded by the smaller mesh would mean that the otter-boards would not spread out satisfactorily, and the net consequently would not fish well, if at all. On the other hand, if the meshes of the square are open to their fullest extent, it is different with the meshes in the wings. As a result of the "slack" at the sides, the meshes there will be extended lengthwise and not so fully open as in the square. The result is that the main rush of water down into the bag is along the sides, and this should be the path the majority of the fish caught in the net will travel.

The greatest difficulty in the working of the otter-trawl is to ensure that the head-line is well off the bottom. If it tends to sag in the centre, the results of the fishing will show that for one thing, and if it bends so far as to touch the ground the rope will be frayed or have some dirt on it. If the mesh in the square were smaller the force of the water when it passed under the head-line would tend to raise the net, but the objections to the smaller mesh are twofold: firstly, if the head-line sagged in any part the pressure of the water would act on the net above the head-line and thus drive it down; and secondly, the smaller the mesh the greater the resistance to the water, and the greater, therefore, the "wave" in front of the net. In neither case would the fishing be a success.

Various patents have from time to time appeared with the intention of overcoming this difficulty. In Epton's patent two large air-bladders, with coating of rubber and surrounded by netting, are fastened one to each top-quarter. In another patent an air-bladder of similar material, but tubular in shape and some 6 to $10 \mathrm{ft}$. long, is attached to the net over the centre of the head-line. It is said by some, however, that the resistance these offer to the water is appreciable. Tanner's idea,* which has been adopted by Petersen and Hjort, to fix glass spheres enclosed in netting round the head-line, would hardly do for professional fishermen. The most recent patent, and one which seems most likely to be successful of any yet tried, is to attach two small otter-boards to the top-quarters and to the main otter-boards in such a way that they would tend to rise in the water, and therefore pull up the head-line.

Another difficulty lies in the choice of the right size of ground-rope to use, though it has been more experienced by naturalists and sailing trawlers than the steamers. In the sailing trawlers the wind may be so light that the boat cannot pull the ground-rope over the bottom fast enough, and mud or stones getting into the net may tear it to pieces. Sometimes also, even with a good breeze, the trawl may come upon a bank of sand or mud which reaches higher than the beam and means

\footnotetext{
* Bull. U.S. Fish Commission, xvi. 1896.
} 
ruin to the trawl. Similar difficulties and experiences have been encountered in the use of Petersen's trawl, but, as will be shown presently, these arise in this case from the nature of the trawl, which, as constructed, courts disaster on soft ground.

Hjort (loc. cit.) has endeavoured to overcome this difficulty in the latter by fixing a stone to the under part of the ground-rope in the centre and counterbalancing it by means of a glass globe above, the idea being, that if the weight of the stone is taken off by rising ground, then the glass globe will lift the ground-rope out of harm's way. Though one would imagine that the stone, by sticking in the mud, would drag the rope down into it likewise, Hjort seems to have found the method successful. Petersen suggests that a thick coir rope should be fastened on the foot-rope when trawling on soft ground, and indeed, the only thing that can be done with Petersen's trawl, if one wishes to use it on soft, muddy ground, is to make the groundrope as light as possible and as large round as possible, then tow over the ground as fast as the trawl will permit. Such is the method of the steam trawlers. They have no special fear of muddy ground, but take care to increase the speed of the vessel.

The otter-trawl, by the large meshes of the net, the thick groundrope, and the high speed it must be towed at, is well adapted for soft ground. A greater difficulty is met with on hard or stony ground. It is essential for good fishing that the ground-rope should grip the ground to some extent, and in order to do this on hard ground all trawlers, whether sailing or steam, reduce speed and at the same time shorten the warps. To do this successfully demands great skill and experience, and in the latter respect the beam-trawlers are many years ahead. It is said, indeed, that they work constantly on rough ground, which the steam trawler avoids after one or two trials. The reason is not far to seek. On rough ground, the roughness is caused not merely by stones, but also by the animal life present, as Lepralia ("Ross"), Alcyonium ("Dead Men's Fingers") on Oysters, Pectens, and such like. The ground-rope of the otter-trawl is quite able to get over these, but their sharp points tear the meshes of the net. The sailing trawlers and the steamers have different devices for overcoming this difficulty. In the former a series of iron rings is suspended all along the ground-rope, and between each ring hangs a short iron chain. There is thus a series of festoons hanging underneath the ground-rope which, at one and the same time, helps the rope to bite into the ground and to break up the material which causes the roughness. To my knowledge, this device has not been adopted, though it may have been tried, on any of the steam trawlers; probably because the great weight the chains add to the 
foot-rope would cause the otter-boards to approach one another, and thus effectually spoil the fishing. Instead, they use a series of "bobbins" or rollers in place of the ordinary bosom of the ground-rope. These are of two sorts-a large, about $15 \mathrm{in}$. in length by $12 \mathrm{in.}$ in diameter, and a small, about $6 \mathrm{in}$. by $4 \mathrm{in}$. The small rollers alternate with the large, and serve for the fixing of the settings of the bosom. Each roller has an iron "bush," i.e. a hollow tube through the centre, and through this is threaded the iron wire which forms the core of the ground-rope. Since these bobbins are not always in use, it is necessary to have some arrangement by which they can be readily shipped and unshipped, and this is done in the following manner. The ground-rope is made in three pieces, and the central part, about $20 \mathrm{ft}$. long, is shackled on to the wings. When the bobbins are to be used, it is a simple matter to unshackle the ordinary bosom of the ground-rope, and shackle on the wire rope with the bobbins.

These add very little, if anything, to the weight of the ground-rope, and are better able to surmount obstacles and break up the hard material on rough ground.

Having thus described the structure of the otter-trawl in detail, it may be of interest to compare it more particularly with other forms of trawls, so as to display wherein its advantages and its limitations lie. It has been shown that the otter-trawl and the beam-trawl are alike in the structure of the bag, batings, pocket, and cod-end, and in having a large square projecting in front. In these particulars they differ from all other forms, and show a distinct improvement. The advantage of the square is that the fish which are feeding on the bottom fauna are well into the net before being disturbed by the ground-rope. If the latter is in advance of the head-line or on a level with it, as in the filets de boeuf and Petersen's trawl, for example, very few of the swifter forms will be captured. Such has been our experience during the past year. The first trawl employed on the Association's steamer Oithona had a square only $8 \mathrm{ft}$. long, and whilst it was an excellent instrument for catching plaice and soles, it was useless, comparatively speaking, for whiting. They were caught, but in no great quantity. Later, when a 24 -foot square was used, the whiting were well represented. As pointed out by Dr. Fulton,* the presence of long wings, and, I may add, the absence of a square, is one of the serious defects of Petersen's trawl.

The advantage of the flapper and pockets, and of the mode of fixing the net which makes them functional, is that once the fish are in the bag of the trawl they cannot escape. In the filets de bouf and similar nets of the Mediterranean, the bag is exceedingly long, and

- Ann. Report Scot. Fishery Board, xx. p. iii. p. 329. 
contracts about $10 \mathrm{ft}$. from the end, like the old-fashioned silk purses, and then expands into the culignon. A great length of bag is here necessary in order to make the net contract and retain the fish. Another method, formerly used in the beam-trawls of this country, was to make several pockets up each side of the net, without a flapper. A further method is that used in the shrimp-trawls of the scientific expeditions of the United States, and adopted more recently by Petersen. It consists of a cone, or funnel, which is laced at its broad end near the front part of the bag, the narrower end hanging open and free towards the cod-end. The under part of this funnel is obviously of doubtful use. It must lie on the belly of the net when trawling and is consequently of no service. If the sides of the funnel were laced along the belly, as described here for the otter-trawl, the under part could be done away with. It is probable, however, that Petersen's trawl would fish just as well without the funnel as with it.

Of the various methods for retaining the fish within the bag, that used in the beam- and otter-trawls seems by far the simplest and most efficient. If the net is properly constructed and properly fixed the fish should have no difficulty in getting into the cod-end, and onee there their natural and well-known tendency to strike upward raises them above the flapper, and they thus cannot escape back into the net. The short bag that is necessary is also a great advantage, as it saves a great deal in the making and repairing of the nets.

The otter-trawl and beam-trawl differ from one another so little that the one may be converted into the other. Remove the beam and iron-heads from the latter, braid on a pair of top-wings to the square, and extend the lower wings correspondingly, and we should have a fairly good otter-trawl. The few differences are of minor importance and are concerned with the kind and manner of fishing. It follows from thence that the results of the fishing depend upon the shape and size of the mouth of the trawl. In the beam-trawl the mouth is rectangular-30 to $40 \mathrm{ft}$. broad or more, and 3 to $4 \mathrm{ft}$. high. In the otter-trawl both the height and breadth are still uncertain. According to the experiments made by Fulton * the breadth from board to board varies between one-half and two-thirds of the possible spread, i.e. a trawl with 90 -foot head-line will have a breadth of mouth between 45 and $60 \mathrm{ft}$. In this respect, therefore, the otter-trawl has only a slight advantage over the largest beam-trawls in use. With regard to the height of the centre of the head-line we have no data on which to base a calculation. If the trawl-mouth is open properly it may vary between 5 and $15 \mathrm{ft}$., and the fisherman's estimate of $10 \mathrm{ft}$. is probably near the mark. This seems to accord with the opinion

* Loc. cit., pp. 120, 121. 
generally held by trawlers, and indicated by the calculations of Garstang* and Fulton, that the otter-trawl catches about 30 per cent. more round fish than the beam-trawl, but the same amount of flat fish. Whatever reliance may be placed on these conclusions, and they are admittedly based on indirect evidence, it is certain that the otter-trawl is not so adaptable for catching flat-fish as the beam-trawl. The high rate of speed which is necessary in the former case in order to keep the mouth of the net open, detracts from its power of catching flat-fish. If the speed is reduced the spread of the mouth will fall below that of the beam-trawl, and the same thing would occur if any extra weight, such as an iron chain or dangles, were attached to the foot-rope as in the beam-trawl, in order to stir up the fish. With respect to size of mesh, also, the otter-trawl is at a great disadvantage in comparison with the beam-trawl. A smaller mesh means less speed, and this, as shown, distinctly affects the fishing capacity of the former, and that adversely, whereas if it affects the beam-trawl it is favourably. The head of the net in the latter is always a fixed height from the ground, and the reduced speed that the smaller mesh demands does not affect the spread.

There can be no doubt, therefore, that for certain purposes the beamtrawl is preferable to the otter, and more especially for small flat-fish. Petersen's trawl, for example, is exceedingly well adapted for this purpose, but it would fish better, I think, and with less trouble, if a beam were attached to it. Its utmost spread appears to be $16 \mathrm{ft}$., but in practice it is probably less, whereas if it were converted into a beam-trawl its spread would be constant and assured. The small size of its mesh-less than 1 in.-makes it comparable, not to an otter-trawl or ordinary beam-trawl, but to the well-known shrimptrawl. In the latter the beam may be of any length between $8 \mathrm{ft}$. and $24 \mathrm{ft}$., and its height from $15 \mathrm{in}$. to $2 \frac{1}{2} \mathrm{ft}$. The size of mesh varies from 1 in. down to $\frac{1}{4} \mathrm{in}$, and in formation the net may be exactly as the ordinary beam-trawl. In place of a wooden beam, however, a hollow iron pipe is better. For deep-sea work in depths greater than 20 fathoms Agassiz' modification of the shrimp-trawl is very useful, because it is immaterial which side it falls on.+

The average speed at which the otter-trawl is towed over the ground is $2 \frac{1}{2}$ knots per hour, the beam-trawl 2 knots, and the shrimp-trawl

\footnotetext{
* Journ. M. B. A., vol. vi. p. $50 . \quad \quad+$ Loc. cit., pp. 122-5.
}

$\ddagger$ Bull. U.S. Fish Commission, xvi., 1896, p. 357. Petersen (loc. cit., p. 6) would have it that the Americans are inclined to return to the single form of shrimp-trawl, but this does not seem warranted. Petersen has slightly misquoted the words of Tanner in the Bulletin cited. According to Tunner, "experts" are able to land the ordinary shrimp-trawl right side up in deep water ; Petersen has it "investigators." There is here a distinction as well as a difference. 
1 mile; it varies according to the ground, the size of mesh, and the length of warp. On hard ground or with smaller mesh or shorter warps it is less than stated, but may be greater with larger mesh and greater length of warp, especially on soft ground.

The dimensions of the commercial trawl-net may be summarised in more compact form :-

Square: 34-40 feet long, 300 meshes down to 200 ; mesh 3 in.

Top-wings: 31-35 feet long, 100 meshes down to 6 or 12 ; mesh 3 in.

Bottom-wings: $68-78$ feet long, 50-55 meshes down to 25-32; mesh 3 in.

Batings: 200 meshes down to 60 ; length, 34 to 36 feet (18 feet to "head of pockets," 10-12 feet of pockets, 6 feet 90 meshes down to 60 ).

Belly and Batings : like the Batings.

Cod-end: 60 meshes across; $1 \frac{1}{2}$ in. mesh; 12 to 18 feet.

Head-rope : $90-100$ feet.

Ground-rope: $120-130$ feet.

Inasmuch as the ordinary commercial otter-trawls are often too large for the steamers at the service of naturalists, it may be of use to give the dimensions of a trawl with 64 feet head-line such as used on the Oithona:-

Square: 26 feet long, 280 meshes down to 180 ; mesh $2 \frac{1}{2}$ in.

Top-wings: 25 feet long, 80 meshes down to $10 ; 2 \frac{1}{2}$ in. mesh.

Bottom-wings : 54 feet long, 50 meshes down to $30 ; 2 \frac{1}{2}$ in. mesh.

Batings; 180 meshes down to $60 ; 24$ feet (first 10 feet to the head of the pockets, 10 feet of pockets, 4 feet 90 meshes down to 60 ); the size of mesh is graded as in the big trawls.

Belly and Batings: 170 meshes down to 60 ; the details otherwise being the same as above.

Cod-end: 60 meshes across in its whole length; 1 in. or $1 \frac{1}{2}$ in. mesh; 8 feet long.

Head-rope: 64 feet.

Ground-rope: 90 feet.

The fixing is just the same as in the large trawls, the square being balched tight to the single head-rope, and 7 to 10 feet of bosom allowed. The ground-rope is $7 \mathrm{in}$. in diameter, and has a central core of iron wire except in the centre of the bosom.

The best method of curing or preserving a net made of manilla twine is to soak it in coal-tar, but if the net is of cotton this makes it unnecessarily heavy, and either cutch alone should be used or cutch 
once or twice, and then light green oil, i.e. creosote oil. The heavy oil of tar, commonly called green oil, is also useful. For hemp nets, cutch and coal-tar seem the best methods. Manilla is employed where rough work has to be done, as in the otter-trawls and larger beam-trawls; cotton and hemp in the smaller beam-trawls and shrimp-trawls.

In the paper referred to,* Dr. Fulton discusses the probability of pelagic fishing with trawls, and concludes that the ideal should have two pairs of otter-boards, so that the mouth and net itself is squareshaped. The practical men, however, seem to have dissuaded him from trying this. As a matter of fact, such a net was experimented with in the North Sea a little more than two years ago with some measure of success.

\section{DESCRIPTION OF DRAWINGS.}

Plate I. Fig. 1.-Drag-seine or Tuck-net, see footnote, p. 567.

Fig. 2.-The method of fixing (balching) a balch-line (b) by means of settings $(s)$ on to a head-line or ground-rope.

Fig. 3.-The method of fixing (marling) the head of the square on to the head-line, and the "flying mesh" in the wings.

Plate II.-Ground-plan of Otter-trawl.

* Twentieth Report, pp. 329 and 330. 


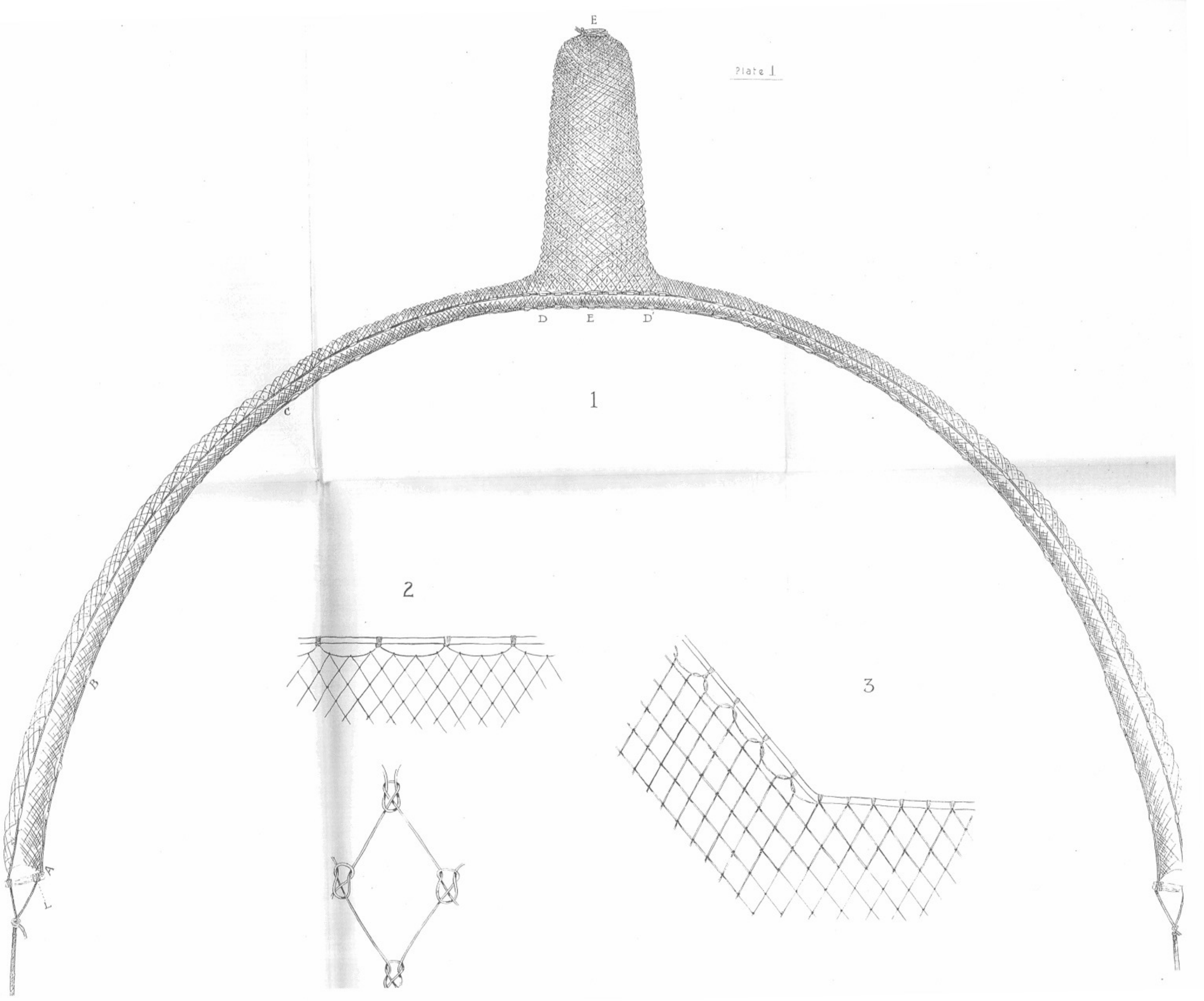




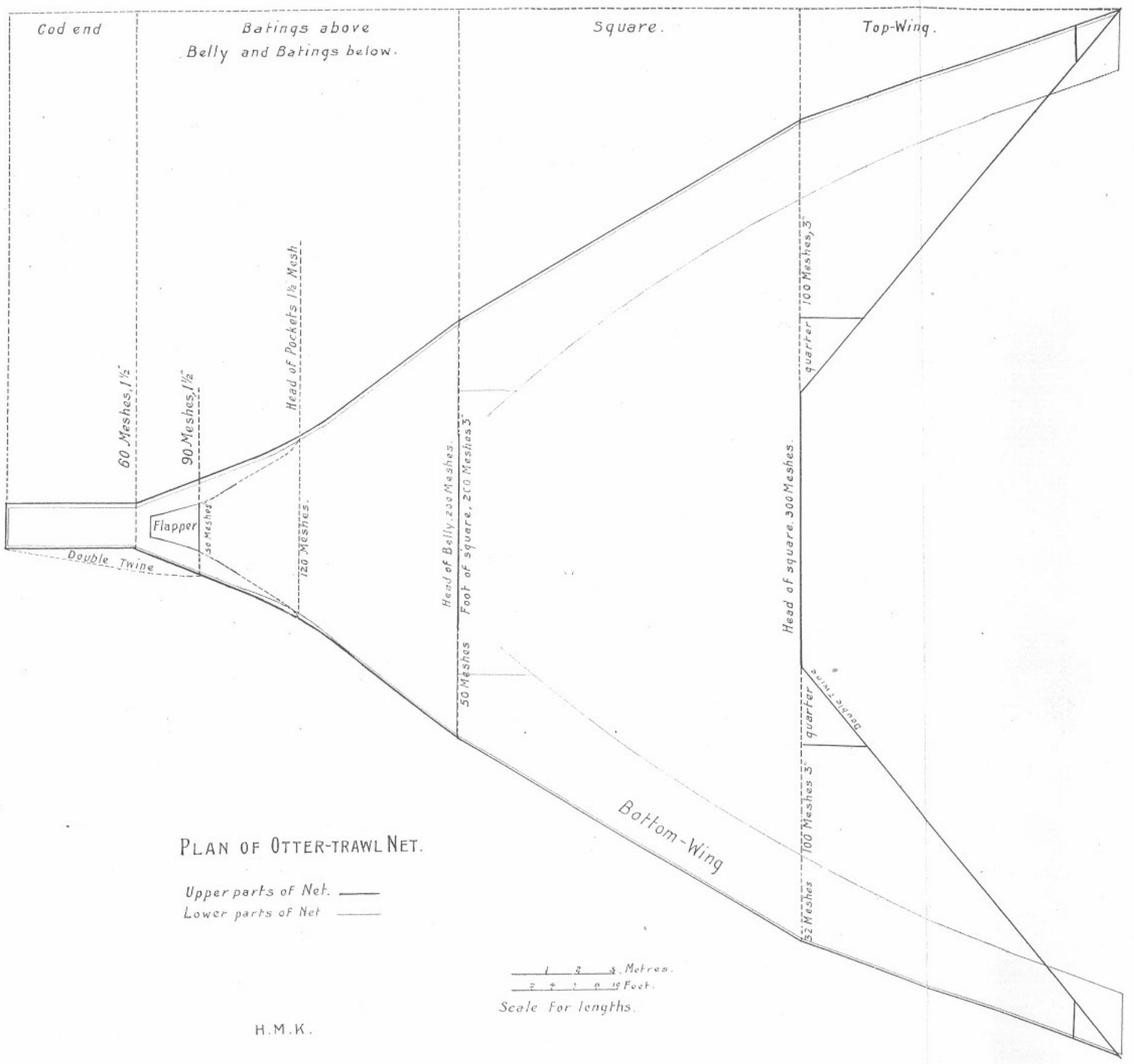

